EPiC Series in Language and Linguistics
Volume 3, 2018, Pages 97-102
LSP in Multi-disciplinary contexts of
Teaching and Research. Papers from the
16th International AELFE Conference

\title{
Préstamos en el recorrido por España de Richard Twiss, un viajero ilustrado
}

\author{
M. Carmen Lario de Oñate, María Vázquez Amador \\ Departamento Filología Francesa e Inglesa, Universidad de Cádiz, Avenida.Dr. Gómez Ulla s/n, Cádiz 11003 \\ carmen.lario@uca.es, maria.vazquez@uca.es
}

\begin{abstract}
Los libros de viaje, existentes desde épocas remotas, permiten al lector conocer parte de esos lugares que se describen. El viaje pasó de ser una necesidad por cuestiones de climatología, de subsistencia, en los primeros tiempos, a ser razón de fortalecimiento de las naciones con la conquista de nuevos territorios en el siglo XV, a convertirse en una experiencia educativa e "ilustrada" de importancia para la clase media-alta británica en los siglos XVII-XVIII a través del Grand Tour. A pesar de que España no formaba parte de ese itinerario de viaje suscitó la curiosidad de algunos viajeros con deseos de saber algo más de ese país desconocido para muchos. Estos intrépidos viajeros dejaron constancia de todo aquello que iban conociendo en libros de viajes, relatos, cartas, etc. y describieron no sólo el patrimonio histórico y artístico sino también su cultura, costumbres, tradiciones y modo de vida.

Este trabajo tiene como objetivo presentar los préstamos utilizados por Richard Twiss, uno de esos aventureros que se lanzó a conocer España a finales del siglo XVIII, a lo largo de las páginas de su obra Travels through Portugal and Spain in 1772 and 1773. A través de este trabajo pretendemos analizar estos vocablos y determinar la procedencia de esos préstamos, si se trata de un fenómeno utilizado con frecuencia en el texto, las áreas temáticas a las que se adscriben y si aparecen con una explicación del significado de la voz o con un equivalente en lengua inglesa.
\end{abstract}

\section{Introducción}

Viajar y conocer nuevos lugares es en la actualidad una de las principales aficiones de un gran número de personas en todo el mundo. No obstante, esta situación es relativamente contemporánea ya que en la antigüedad los desplazamientos se debían a distintas razones como la búsqueda de mejores condiciones de vida, lugares donde la subsistencia fuera más fácil, razones comerciales e incluso las grandes conquistas. Ya a partir de finales del siglo XVII, y fundamentalmente en el siglo XVIII, el viaje empezó a ostentar un cariz educativo, es el viaje ilustrado (Aguilar Piñal, 1991; Gómez de la Serna, 1971; Guerrero, 1990). Una gran mayoría de esos viajeros ilustrados eran de origen británico y el itinerario establecido más popular era el Grand Tour que recorría parte de Europa, aunque España no formaba parte de él. No obstante, fueron muchos los viajeros que se adentraron en estas tierras en su afán de conocer distintos lugares y entre ellos se encuentra Richard Twiss. Twiss nació en Rotterdam en 1747, hijo de un 
acaudalado comerciante inglés de Norwich. Desde muy joven se aficionó a viajar y antes de cumplir los 25 años ya había recorrido diversos países europeos. En 1772-1773 visitó España y en 1775 publicó Travels through Portugal and Spain in 1772 and 1773. Los recorridos que realizó lo llevaron a ir conociendo parte de las culturas y lenguas de esos países que visitó, lo cual impregnará las distintas obras que escribe. Estos testimonios son de mucho interés porque evidencian la diferencia entre lo propio y lo ajeno, es decir, reflejan las diferencias entre las distintas culturas (Hoyas, 2005). Una de las consecuencias de estas diferencias culturales es la inclusión de préstamos lingüísticos en estos relatos de viajes. Estos préstamos pueden proceder de disciplinas como la geografía, las artes, la gastronomía, etc. (Calvi, 2010). Esta idea coincide con la teoría del triple camino de Meillet, que sostiene que los préstamos no entran directamente en la lengua general, sino que normalmente son términos que pertenecen al lenguaje específico de la lengua de origen (Gómez Capuz, 2000).

El Diccionario de la Lengua Española en su versión en línea define préstamo como "Elemento, generalmente léxico, que una lengua toma de otra". Pese a que todas las lenguas son proclives a la adopción de vocablos extranjeros, el inglés tiene una capacidad especial para tomar prestadas palabras de otros idiomas (Crystal, 1997) y este hecho se observa claramente con el alto número de voces de procedencia foránea aceptadas en cualquier diccionario de lengua inglesa (Durkin, 2014).

Aunque existen diversos estudios sobre el lenguaje del turismo (Dann, 1996; Carpi, 2010; Calvi, 2006; Estornell, 2013; Durán Muñoz, 2014, entre otros) no son tan comunes las investigaciones que se centran en los préstamos lingüísticos en libros de viaje escritos en inglés (López Zurita, 2003, González Cruz, 2011; y De la Cruz et al, 2015). Esa es una de las razones por las que decidimos trabajar sobre este tema, con el objetivo de investigar qué tipo de préstamos se localizan en una guía de viaje del siglo XVIII, de qué lengua proceden estos préstamos, a qué áreas temáticas pertenecen y si hacían referencia a conceptos muy ligados a la cultura del país descrito o eran voces que podían traducirse con facilidad a otras lenguas.

\section{El estudio}

El objetivo de este trabajo es analizar los préstamos utilizados por Richard Twiss en las páginas dedicadas al recorrido por tierras españolas en la obra Travels through Portugal and Spain in 1772 and 1773, si bien las primeras 56 páginas dedicadas al país luso no serán objeto de estudio. El libro va siguiendo la ruta de los lugares que va visitando desde que comienza en Ciudad Rodrigo, procedente de Lisboa, hasta llegar a Cádiz de donde parte de vuelta a Gran Bretaña con rumbo a Dover. Twiss va recorriendo caminos, visitando ciudades y describe todo aquello que va observando haciendo referencias históricas, literarias, científicas, referentes al clima, flora y fauna, transporte, idioma, religión, naturaleza, costumbres, etc.

El corpus objeto de estudio ha sido recopilado y agrupado por idiomas y campos léxicos. Se localizaron un total de 130 préstamos lingüísticos. No se han incluido en este recuento nombres propios de personas o de lugares si no incluían alguna traducción o explicación del término, inscripciones en objetos o lugares ni títulos de libros. Sí se han incluido expresiones utilizadas en otras lenguas que estaban insertadas en los textos. En cuanto a las lenguas de procedencia, indudablemente la lengua más utilizada ha sido la española (94), seguida con notable diferencia por francés (14), italiano (12), latín (9) y alemán (1) como se aprecia en el gráfico 1. 


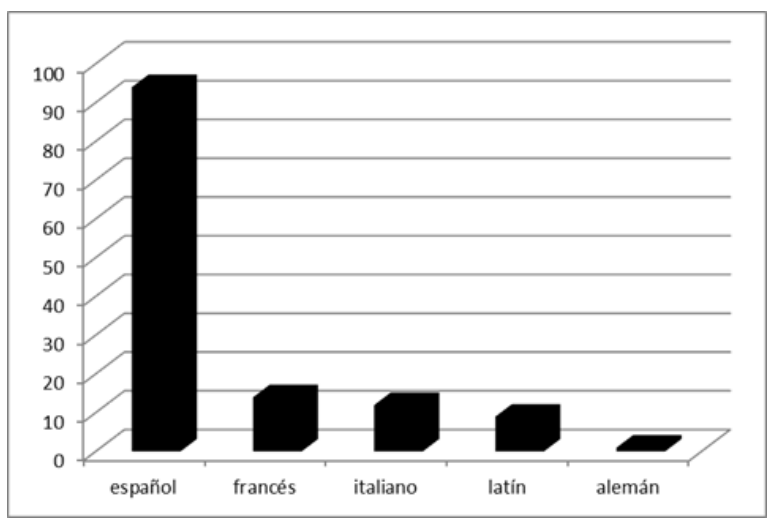

Gráfico 1: Procedencia de los préstamos.

Tan solo se encontró un préstamo procedente del alemán, Leyer, que aparece en el texto junto con su equivalente francés, Vielle. Ambos cumplen una función referencial pues el autor los utiliza para describir un instrumento musical español.

[...] I observed one of two angels playing on a musical instrument, somewhat like that called by the French Vielle, Leyer by the Germans, and Beggar's Lyre by Dr. Burney; one of the angels plays with his fingers on the keys, of which there are ten, and the other turns the handle (p. 65).

Se localizaron nueve préstamos derivados del latín. Algunos de ellos se utilizaban como sinónimos explicativos ("the pastoral crook (pedum)", p. 95) mientras otros eran expresiones latinas intercaladas en el texto ("having drank quantum sufficit", p. 235) e incluso citas de autores clásicos, como una de Quinto Horacio Flaco, (“Risum teneatis amici!", p. 172).

Doce de los préstamos encontrados procedían del italiano que en su mayoría están relacionados con la música, la pintura y la escultura, es decir, con las artes: "I myself remember to have seen in the church of our Lady of the Stairs, or Ladder (Madonna della Scala), in Parma [...]" (p. 172). Asimismo se localizó un italianismo que hacía referencia a la gastronomía, concretamente a una verdura y venía acompañado de su homólogo francés en una curiosa descripción del autor sobre los tomates: "[...] and tomates; these last are a sort of apple of a scarlet colour, and of a very tart flavour; they grow likewise in the southern parts of Italy and France, where they are called marignani and pommes d' amour." (p. 255).

En cuanto a los 14 préstamos procedentes del francés, 4 se relacionan con las artes ("The celebrated Venus Aphrodite, kneeling with one knee on a large shell, called by the French la Venus aux belles fesses; nine statues ; six busts", p. 95), los demás se reparten entre transportes ("There are no hackney coaches in Madrid but carosses de remise", p. 157), gastronomía, que normalmente se utilizan para esclarecer productos o comidas que no existen en Inglaterra ("[...] and supped on gaspacho. This is an excellent kind of soupe-maigre, than which nothing can be more cooling or refreshing during the violent heats", p. 278); y los dedicados a personas, juegos, etc.

Como era de esperar, el número de hispanismos era infinitamente superior al de los préstamos de otras lenguas y se adherirían a diversas áreas temáticas: flora y fauna, lugares, monedas y medidas, expresiones y costumbres, artes, alimentos, religión, toreo, construcciones, juegos, transporte y vocablos referidos a personas. Los hispanismos que más se repiten en la obra son los pertenecientes a los campos léxicos de flora y fauna; lugares; y monedas y medidas. Twiss como miembro de la Royal Society, sociedad científica fundada en el siglo XVII para la difusión del conocimiento, era una persona versada sobre muy diversos temas y entre ellos la botánica, por 
ello, en sus páginas abundan las referencias detalladas sobre variadas plantas: "[...] they carried slints, steels, and a kind of tinder, called yesca, which consists of white filaments of a certain plant, to light their tobacco with.” (p. 297).

Entre los hispanismos referidos a lugares destacan aquellos que menciona en español con su correspondiente equivalente en inglés, "The Spaniards call it el Puente, or the Bridge, which is a very improper name" (p. 83); haciendo referencia al Acueducto de Segovia. Otro ejemplo muy significativo es el que expone sobre El Escorial en su visita a este municipio: "The village which gave name to this palace, is called El Escorial, derived from the Spanish word Escoria, which signifies the scum of melted metal, because formerly some iron mines were worked here" (p. 99).

Con respecto a monedas y medidas, en la mayoría de los casos vienen acompañadas de una explicación en la que se ilustra cuál sería el equivalente en Inglaterra, ("thirty arrobes of fruit (each arrobe is twenty-fix pounds)", p. 217).

Varias voces hacían referencia a costumbres españolas como la siesta ("having hecho la siesta, that is, slept two hours after dinner", p. 270), el cortejo o la tertulia. Asimismo se localizaron diversas expresiones como "Viva V.S. mil años", que según el autor es el equivalente a "I thank you", como se explica en el siguiente fragmento: "For "I thank you" the Spaniards say "Viva V.S. mil años" "May your worship live a thousand years"” (p. 334).

Diez fueron los hispanismos relacionados con las artes, normalmente en el contexto del arte religioso ("a very fine Custodia d'ostia of silver filagrana," p. 110) y del flamenco ("Between the comedy and the farce, tonadillas are sung: these are cantatas for two, three or four voices", p. 167). También se encontraron diversos referidos a personas (" $[\ldots]$ his beautiful lady and another señora,", p. 260), ("[...] hate each other as the Spanish and the French: these are in Spain called Gavachos", p.142).

Siete de los hispanismos se referían a alimentos, frutas e incluso comidas que en ese momento histórico no tienen un equivalente en lengua inglesa y necesitan consecuentemente ser explicados ("garbanzos (which are a kind of pease)", p. 255).

Asimismo se localizaron hispanismos relacionados con la religión y con el toreo en el que se explican las distintas partes de la corrida y el rol de los participantes ("Three men on horfeback were to encounter the bull; these are called picadores, jockeys", p. 290).

El resto de los hispanismos estaban relacionados con la arquitectura ("[...] and three rows of entrances (vomitorios)", p. 208), con los juegos ("The Spaniards have may other games, such as lotteries, biribis, [...]", p. 238) y con el transporte ("I went in a coach, which the Spaniards call galera [...]", p. 318).

\section{Conclusiones}

Tras un minucioso análisis de los préstamos lingüísticos localizados en la obra Travels through Portugal and Spain in 1772 and 1773 de Richard Twiss se puede concluir que el número de voces extranjeras es bastante significativo. Aunque se encontraron préstamos lingüísticos que procedían de distintas lenguas, los hispanismos destacaron cuantitativamente y cualitativamente. En cuanto a las áreas temáticas, la más relevante fue la de las artes, con un total de 24 voces, procedentes de todas las lenguas incluidas en el estudio. El autor describía elementos de la pintura, música y escultura española y de otros países europeos, fundamentalmente de Italia, demostrando su conocimiento y gusto por el arte. Los préstamos relacionados con la religión procedían principalmente del español y en menor medida del latín y del italiano y los del transporte del francés y del español. También se localizaron diversos préstamos relacionados con la flora y la fauna, y vocablos relacionados con distintos lugares, en esta ocasión la mayor parte de ellos procedían naturalmente del español y se utilizaron, probablemente, por no haber un término exacto 
en inglés y normalmente iban acompañados de una explicación. Las monedas y medidas utilizadas eran hispanismos e iban generalmente seguidas de un equivalente en lengua inglesa, al igual que los términos relacionados con el toreo. En cuanto a los alimentos, la mayor parte de los localizados eran nuevamente hispanismos, y los procedentes del francés y del italiano aparecían junto a sus homólogos en español, quizá como un intento del autor de clarificar una realidad no existente en su país de origen. Con el análisis de los 130 préstamos lingüísticos localizados se evidencia la capacidad de la lengua inglesa de adoptar términos en otras lenguas, Richard Twiss, como viajero ilustrado, nos dejó un legado de gran importancia para el conocimiento de la España del siglo XVIII. Debido a sus muchos viajes realizados y el conocimiento adquirido en ellos supo plasmar a través de sus observaciones y descripciones todo aquello que podía resultar de interés a la persona que viajara a nuestro país. A través del lenguaje utilizado es posible detectar su dominio de términos en diferentes lenguas, algo de lo que probablemente él mismo se enorgulleciera.

\section{Referencias bibliográficas}

Aguilar Piñal, F. (1991). Introducción al siglo XVIII. Madrid: Júcar.

Calvi, M. V. (2006). El uso de términos culturales en el lenguaje del turismo: los hoteles y su descripción. En Calvi, M. V. y Chiexichetti, L. (Eds.), Nuevas tendencias en el discurso de especialidad (pp. 271-292). Berna: Peter Lang.

Calvi, M. V. (2010). Los géneros discursivos en la lengua del turismo: una propuesta de clasificación. Ibérica, 19, 9-32.

Carpi, E. (2010). Las denominaciones de los establecimientos de alojamiento turístico en la normativa española . En Chierichetti, L. y G. Garofalo (Eds.) Lengua y derecho: líneas de investigación interdisciplinaria (pp. 65-91). Berna: Peter Lang.

Crystal, D. (1997). English as a Global Language. Cambridge: Cambridge University Press.

Dann, G. (1996). The Language of Tourism. A Sociolinguistic Perspective. Oxon, UK: CAB International.

De la Cruz Cabanillas, I.; Mancho Barés, G. \& Tejedor Martínez, C. (2008). Los anglicismos en el lenguaje del turismo. Procedimientos de formación de palabras. En P. Sánchez Fernández (Ed.), Researching and teaching specilized languages: New contexts, new challenges (pp. 238-248). Murcia: Servicio de Publicaciones de la Universidad de Murcia.

Durán Muñoz, I. (2014). Aspectos pragmático-lingüísticos del discurso del turismo de aventura: estudio de un caso. Normas. Revista de estudios lingüísticos hispánicos, 4, 49-69.

Durkin, P. (2014). Borrowed Words. A History of Loanwords in English. Oxford: Oxford University Press.

Estornell Pons, M. (2013). Aproximación al léxico del turismo activo: codificación lexicográfica, formación y variación denominativa. Normas. Revista de estudios lingüísticos hispánicos, 3, 33-55.

Gómez Capuz, J. (2000). Anglicismos léxicos en el español coloquial. Cádiz: Servicio de Publicaciones de la Universidad de Cádiz.

Gómez de la Serna, G. (1971). Los viajes de la Ilustración, Madrid: Alianza Editorial.

González Cruz, M. I. (2011). Hispanismos y canarismos en los textos de dos viajeras inglesas decimonónicas. Revista de Filología, 29, 81-99.

Guerrero, A. C. (1990). Viajeros británicos en la España del siglo XVIII. Madrid: Aguilar.

Hoyas Solís, J. (2005). Salamanca y su universidad en los relatos de viaje ingleses del siglo XVIII. Anuario de estudios filológicos, 28, 117-129. 
López Zurita, P. (2003). Estudio semántico de las interferencias inglés/español en Gatherings from Spain, de Richard Ford. Tesis doctoral, Universidad de Cádiz. 